\title{
A RE-EXAMINATION OF THE ANTIGONADAL EFFECT OF PROLACTIN IN THE MALE FOWL, GALLUS DOMESTICUS
}

\author{
J. SHANI,* B. J. A. FURR $†$ AND ISABEL A. FORSYTH \\ National Institute for Research in Dairying, \\ Shinfield, Reading RG2 9AT
}

(Received 11th Fanuary 1973)

Injection of prolactin into adult cocks has been reported to decrease testis weight, tubule diameter and androgen production, resulting in decreased comb size and cessation of crowing (Nalbandov, 1945). Similar inhibitory effects of prolactin on the gonads were observed in male chicks (Breneman, 1942) and in laying and non-laying hens (Bates, Lahr \& Riddle, 1935). This antigonadal effect is thought to be produced by inhibition of pituitary FSH secretion, since injection of FSH with prolactin prevented gonadal regression (Nalbandov, 1945). There are a number of other species of birds in which antigonadal effects of prolactin have been described (see Meier \& Dusseau, 1968). Recent findings, however, indicate a complex interplay of hormones regulating gonadal growth and regression (Meier, Martin \& MacGregor, 1971) and there seem to be some avian species in which prolactin fails to inhibit the gonads, e.g. California quail, Lophortyx californicus (Jones, 1969) and whitecrowned sparrows, Zonotrichia leucophrys gambelii (Laws \& Farner, 1960). In view of these observations and the availability of more highly purified ovine prolactin than was used in the earlier studies, it was decided to reinvestigate the effect of prolactin on the testes of the adult cock. All the birds used were adult, fertile cocks obtained from Thornbers Ltd, Twyford, Reading, Berks., and were 11 to 18 months old. They were housed individually, allowed free access to food and water and were exposed to $14 \mathrm{hr}$ light/day, from 04.00 to 18.00 hours.

In the first experiment, twelve Rhode Island-type cocks (male parent of Thornber 404) were divided at random into three groups of four cocks each. The groups received a single daily subcutaneous injection of $1 \mathrm{ml}$ saline, or prolactin (NIH-P-S-6), 8 i.u. or 80 i.u./day in $1 \mathrm{ml}$ saline. Two cocks in each treatment group were injected for 10 days and killed on Day 11 ; the remainder were injected for 22 days and killed on Day 23. Body weight and comb dimensions (length $\times$ maximal height) were recorded initially and on Days 11 and 23 . A blood sample was taken from eleven of the twelve cocks before injection began and blood was also collected at autopsy. Testosterone levels were measured by gas-liquid chromatography of the iodomethyldimethylsilyl ether

* Present address: School of Pharmacy, The Hebrew University, P.O.B. 12065, Jerusalem, Israel.

$\uparrow$ Present address: ICI Pharmaceuticals Division, Alderley Park, Macclesfield, Cheshire. 


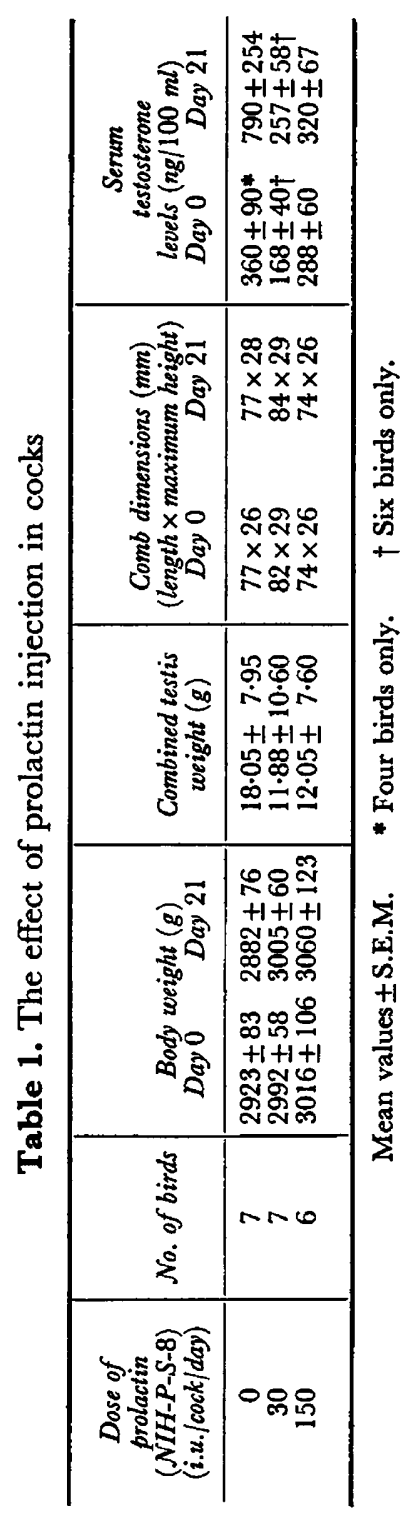


derivatives (Furr \& Thomas, 1970). Testes were removed at autopsy, weighed, fixed in formol saline and examined histologically. An essentially similar experiment was carried out using ten White Leghorn cocks and in neither experiment was there any evidence of an antigonadal effect of prolactin. In a third experiment, twenty White Leghorn cocks were used and higher doses of prolactin (0,30 or 150 i.u./day) were administered once daily for 20 days, autopsy being performed on Day 21. The full results of this experiment are shown in Table 1. Even these massive doses of prolactin had no effect on body weight, testis weight or comb dimensions. Testosterone levels were very variable, but there was no indication of a diminished ability to secrete the hormone in prolactin-treated birds. Histological examination of the testes showed spermatogenesis with spermatid and sperm formation in all birds. Some testes showed areas of variable size in which some involutionary changes were occurring, but this was unrelated to prolactin treatment and probably reflected the age of the birds.

These experiments, therefore, fail to confirm the results of Nalbandov (1945), although there are several possible explanations for this. The preparation of prolactin used by Nalbandov (1945) was tested and found to have low FSH activity. Nevertheless, it is possible that trace contamination with FSH could have led to antibody formation in the injected animals and inhibition of the biological activity of endogenous circulating FSH. Alternatively, genetic dissimilarities in the birds used in the two studies could be responsible. The male birds in Nalbandov's studies exhibited broodiness in response to injected prolactin, whilst the birds used by us were of commercial strains selected not to show broodiness in hens. It is possible that in the course of breeding out the broody trait, the indirect testis response to prolactin, mediated through the hypothalamus and/or pituitary, has been lost. Finally, it is possible that we injected prolactin at the wrong time in the photoperiod to achieve testis regression. Nalbandov (1945) gave two daily injections: one in the morning, and one in the afternoon. Injections in the present experiment were made between 11.00 and 13.00 hours. Subsequently, Meier et al. (1971) have shown that prolactin injected into sparrows can produce either gonadal growth or inhibition, depending on when it is injected in the photoperiod. The nature of the response is influenced by the plasma levels of adrenal corticosteroids which exhibit a circadian rhythm. It is clear that the entire question of the antigonadal effect of prolactin in Gallus domesticus requires detailed reinvestigation.

We wish to thank the U.S. National Institutes of Health for the gift of sheep prolactin, Dr B. S. Thomas, Imperial Cancer Research Fund, London, for assistance with the testosterone assays, $\mathrm{Mr}$ A. Turvey for the preparation of histological material and Mrs Maureen Barrett for skilled technical assistance. One of us (J.S.) was the recipient of a Royal Society Travelling Fellowship and B.J.A.F. held a British Egg Marketing Board Postdoctoral Fellowship.

\section{REFERENCES}

BATES, R. W., LAHR, E. L. \& RiddLe, O. (1935) The gross action of prolactin and follicle-stimulating hormone on the mature ovary and sex accessories of fowl. Am. F. Physiol. 111, 361. 
BRENEMAN, W. R. (1942) Action of prolactin and estrone on weights of reproductive organs and viscera of the cockerel. Endocrinolog, 30, 609.

Furr, B. J. A. \& Thomas, B. S. (1970) Estimation of testosterone in plasma of the domestic fowl. 7. Endocr. 48, xlii.

Jones, R. E. (1969) Effect of prolactin and progesterone on gonads of breeding California quail. Proc. Soc. exp. Biol. Med. 131, 172.

Laws, D. F. \& Farner, D. S. (1960) Prolactin and the photoperiodic testicular response in whitecrowned sparrows. Endocrinology, 67, 279.

Merer, A. H. \& Dusseau, J. S. (1968) Prolactin and the photoperiodic gonadal response in several avian species. Physiol. Zoöl. 41, 95.

Meier, A. H., Martin, D. D. \& MacGregor, R. (1971) Temporal synergism of corticosterone and prolactin controlling gonadal growth in sparrows. Science, N.Y. 173, 1240.

Nalbandov, A. V. (1945) A study of the effect of prolactin on broodiness and on cock testes. Endocrinology, 36, 251. 